\title{
PENGARUH INTERAKTIF ANTARA FAKTOR INDIVIDUAL DAN KONDISI INSTITUSIONAL TERHADAP ENTREPRENEURIAL ENGAGEMENT
}

\author{
(THE INTERACTIVE EFFECTS BETWEEN INDIVIDUAL FACTORS \\ AND INSTITUTIONAL CONDITIONS ON \\ ENTREPRENEURIAL ENGAGEMENT)
}

\author{
Oleh: \\ Riana Susanti' ${ }^{1)}$, Askardiya Radmoyo Adji ${ }^{2)}$ \\ Sekolah Tinggi Ilmu Ekonomi IPWI Jakarta1,2) \\ santihoesodo@gmail.com ${ }^{1)}$, ahoesodo@gmail.com ${ }^{2)}$
}

Submit: 03 Jul 2019

Review: 05 \& 11 Aug 2019

Accept: 15 Aug 2019

\begin{abstract}
The purpose of this study is to investigate the direct influence of individual factors including individuals' income and individual education levels on entrepreneurial engagement, as well as the influence of institutional conditions, including government policy and universities supports on the relationship between individual factors and individuals' entrepreneurial engagement. Cross sectional study was used to test the research hypotheses. The data was collected through questionnaires which were distributed to Members of Indonesian Chamber of Commerce and Industry in Jakarta where the industries and investment activities are centralized. A random sample of 345 members was used to collect the data. The response rate was 91\%. The results show a significant positive direct effect of individual factors on the entrepreneurial engagement. Institutional conditions, including government policy and universities supports, have a positive effect on the relationship between individual factors and entrepreneurial engagement. This research is useful for prospective entrepreneurs in Indonesia so that they can utilize the resources they have in the entrepreneurial engagement process. Likewise it will help the institutional parties that influence the process of entrepreneurial engagement in creating entrepreneurial atmosphere and culture.

Keywords: Individual Factors, Institutional Conditions, Entrepreneurial Engagement, Entrepreneurship in Indonesia
\end{abstract}

\begin{abstract}
ABSTRAK
Tujuan dari penelitian ini yaitu untuk menyelidiki pengaruh langsung faktor individual, meliputi tingkat pendapatan dan pendidikan individu terhadap entrepreneurial engagement, termasuk pengaruh kondisi institusional, meliputi kebijakan pemerintah dan dukungan universitas, terhadap hubungan antara faktor individual dan entrepreneurial engagement. Studi cross sectional digunakan untuk menguji hipotesis. Data dikumpulkan melalui kuesioner yang didistribusikan kepada anggota Kadin Jakarta dimana kegiatan industri dan investasi terpusat. Sampel acak sebanyak 345 anggota digunakan
\end{abstract}


untuk mengumpulkan data. Tingkat respon sebanyak 91\%. Hasil menunjukkan pengaruh langsung faktor individual signifikan positif terhadap entrepreneurial engagement. Kondisi institusional, meliputi kebijakan pemerintah dan dukungan universitas berpengaruh positif dalam hubungan antara faktor individual dan entrepreneurial engagement. Penelitian ini berguna untuk calon wirausaha di Indonesia sehingga mereka dapat memanfaatkan sumber daya yang dimiliki dalam proses entrepreneurial engagement. Begitu juga akan membantu pihak insitusional yang mempengaruhi proses entrepreneurial engagement dalam penciptaan suasana dan budaya kewirausahaan.

Kata Kunci: Faktor Individual, Kondisi Institusional, Entrepreneurial Engagement, Kewirausahaan di Indonesia

\section{PENDAHULUAN}

Indonesia memiliki tingkat pengangguran yang tinggi sebanyak 5.5\% pada 2016 dibandingkan dengan negaranegara tetangga, seperti Malaysia dan Singapore, yang memiliki tingkat pengangguran lebih rendah (Economics, 2016)

Dalam hal ini, perkembangan ekonomi di negara-negara berkembang, seperti Indonesia sangat dipengaruhi wirausaha, karena wirausaha menciptakan pekerjaan dan kesejahteraan.

Berdasarkan Kementerian Koperasi dan UMKM, tingkat kewirausahaan di Indonesia hanya sebanyak $1.65 \%$ dari total populasi, masih rendah dibandingkan dengan negara-negara tetangga, seperti Malaysia dan Singapore, yang memiliki tingkat kewirausahaan lebih tinggi (Furinto, 2015)

Indonesia terklasifikasi sebagai negara berpenghasilan rendah menengah oleh World Bank. Sementara modal finansial memiliki peran langsung dan instrumental terhadap proses kewirausahaan pada tingkat individual ( $\mathrm{Lim}, \mathrm{Oh}$, \& Clercq, 2016)

Faktor kunci lainnya dalam proses kewirausahaan pada tingkat individual yaitu tingkat pendidikan ( $\mathrm{Lim}, \mathrm{Oh}, \&$ Clercq, 2016). Modal intelektual memiliki peran dan dapat meningkatkan kemampuan individu untuk menangkap peluang (Ucbasaran, Westhead, \& Wright, 2008)

Menurut World Bank, Indonesia mendapatkan peringkat ke-91 dalam kemudahan berbisnis dan peringkat ke-151 dalam memulai bisnis dari 190 negara (Praditya, 2016). Dalam hal ini, peran pemerintah dan institusi lain, seperti universitas, sangat penting untuk membangun suasana dan budaya berwirausaha yang menguntungkan di negara.

Penelitian ini berfokus pada bagaimana faktor individual, meliputi tingkat pendapatan dan pendidikan individu, mempengaruhi entrepreneurial engagement, termasuk pengaruh kondisi institusional, meliputi kebijakan pemerintah dan dukungan universitas, terhadap hubungan antara faktor individual yaitu tingkat pendapatan dan pendidikan dan entrepreneurial engagement.

\section{TUJUAN PENELITIAN}

Penelitian ini bertujuan untuk:

1. Menganalisis pengaruh faktor individual, meliputi tingkat pendapatan dan pendidikan individu terhadap entrepreneurial engagement.

2. Menganalisis pengaruh kondisi institusional, yaitu kebijakan pemerintah, terhadap hubungan antara faktor individual yaitu tingkat 
pendapatan dan tingkat pendidikan dengan entrepreneurial engagement.

3. Menganalisis pengaruh kondisi institusional, yaitu dukungan universitas, terhadap hubungan antara faktor individual yaitu tingkat pendapatan dan tingkat pendidikan dengan entrepreneurial engagement.

\section{TELAAH LITERATUR DAN PENGEMBANGAN HIPOTESIS Kewirausahaan}

Menurut Stephen P Robbins dan Mary Coulter, kewirausahaan adalah proses dimana seorang individu atau kelompok individu menggunakan upaya terorganisir dan sarana untuk mengejar peluang untuk menciptakan nilai dan tumbuh dengan memenuhi keinginan dan kebutuhan melalui inovasi dan keunikan, tentang masalah sumber daya apa yang saat ini dikendalikan (Syaifuddin, 2016). Dalam kewirausahaan kondisi ekonomi, sosial, institusional, dan faktor penting lain secara interaktif mempengaruhi penciptaan dan penemuan, termasuk eksploitasi peluang kewirausahaan (Qian, Acs, \& Stough, 2013).

Penelitian lain menunjukkan hubungan antara kewirausahaan dengan perkembangan ekonomi. Hal tersebut dibedakan berdasarkan pada tingkat analisis, meliputi tingkat mikro, meso dan tingkat makro (Shepherd, 2010). Tingkat mikro membicarakan kondisi kewirausahaan terdiri atas psikologi yang mencakup perilaku, tindakan, dan keterampilan yang akan menuntun pada aktualisasi diri atau kesejahteraan individu. Tingkat meso atau tingkat perusahaan terdiri atas insentif budaya bisnis yang merupakan elemen penting untuk memulai masuk pasar baru dan inovasi yang akan menuntun kinerja perusahaan. Tingkat makro kondisi yang dibutuhkan yaitu institusi dan budaya.

Elemen penting kewirausahaan pada tingkat makro yakni berbagai daya saing yang selektif, hal tersebut akan menuntun pada dampak kewirausahaan yang hasilnya pertumbuhan daya saing dan ekonomi.

\section{Pengaruh Faktor Individual terhadap Kewirausahaan}

Penciptaan bisnis baru sebenarnya mencakup keterlibatan individu dalam penemuan peluang, evaluasi, dan eksploitasi (Haynie, Shepherd, \& McMullen, 2009). Penemuan peluang mengacu pada tahap ketika individu merasakan keberadaan peluang kewirausahaan.

Banyak faktor dibutuhkan untuk aktivitas kewirausahaan, seperti tingkat pendapatan dan pendidikan, pada individu (Autio \& Acs, 2010). Sehingga hal yang penting adalah yang mana tingkat pendapatan dan pendidikan individu dapat dihubungkan dengan kewirausahaan. Isu ini cukup menonjol di negara-negara berkembang dimana eksploitasi sumber daya sering dihalangi oleh kondisi institusional (Lau \& Busenitz, 2001)

\section{Tingkat Pendapatan}

Modal finansial memiliki peran langsung dan instrumental terhadap proses kewirausahaan pada tingkatan individu (Lim, Oh, \& Clercq, 2016)

Tingkat pendapatan merupakan salah satu tuas pada stratifikasi sosial, seperti kelompok sosial yang memiliki tingkat pendapatan tinggi mendapatkan akses terhadap informasi berkualitas tinggi terkait peluang kewirausahaan (Lim, Oh, \& Clercq, 2016). 


\section{Tingkat Pendidikan}

Penelitian sebelumnya mengindikasi bahwa tingkat pendidikan individu memainkan peranan penting dalam menstimulisasi kewirausahaan di negaranegara berkembang, berdasarkan pada beberapa aktivitas alternatif yang mana modal intelektual digunakan (Iyigun \& Owen, 1998).

\section{Pengaruh Kondisi Institusional terhadap Kewirausahaan}

Hubungan kondisi institusional terhadap kewirausahaan ditunjukkan dalam penelitian sebelumnya yang menggunakan konsep dimensi kebijakan dan kognitif pada konteks institusional untuk menguji keterkaitan antara tingkat pendapatan dan pendidikan terhadap keterlibatan kewirusahaan individu (Busenitz, Gomez, \& Spencer, 2000)

Dimensi kognitif mencerminkan tingkatan dimana pengetahuan berkaitan kewirausahaan tersebar dalam negara, seperti tingkat kesadaran terhadap pertumbuhan dan perkembangan bisnis baru dalam sistem pendidikan negara system (Levie \& Autio, 2008). Dalam hal ini, pemerintah dan universitas mencoba untuk menciptakan lingkungan dengan inovatif yang tinggi dimana wirausaha muda tergerak berinovasi, kemudian meningkatkan perekonomian (Jansen, Zande, Brinkkemper, \& Varma, 2015).

\section{Kebijakan Pemerintah}

Dimensi regulasi mempengaruhi proses kewirausahaan melalui berbagai langkah kebijakan (Bruton, Ahlstrom, \& Li, 2010). Jenis dan tingkat kewirausahaan dipengaruhi kebijakan publik yang dimanfaatkan secara positif. Kebijakan dan insentif kewirausahaan yang ramah dapat secara efektif mengurangi hambatan terhadap aktivitas kewirausahaan (Baumol, Litan, \& Schramm, 2009)

\section{Dukungan Universitas}

Dimensi kognitif menangkap kategori pengetahuan yang dibagikan kepada individu dalam negara (Kostova \& Roth, 2002) dan mencerminkan tingkatan yang mana pengetahuan terkait kewirausahaan tersebar secara luas dalam konteks penciptaan bisnis baru (Busenitz, Gomez, \& Spencer, 2000).

Perhatian terhadap kewirausahaan dalam pendidikan tinggi mungkin tidak hanya mempersiapkan individu untuk mengembangkan keterampilan kewirausahaan, tetapi juga menyebarkan kesadaran kewirausahaan sebagai pilihan karir yang mungkin (Souitaris, Zerbinati, \& Al-Laham, 2007).

\section{Kerangka Penelitian}

Kerangka penelitian untuk menganalisis pengaruh faktor individual dan kondisi institusional terhadap entrepreneurial engagement dapat di digambarkan sebagai berikut:

Gambar 1

Kerangka Penelitian

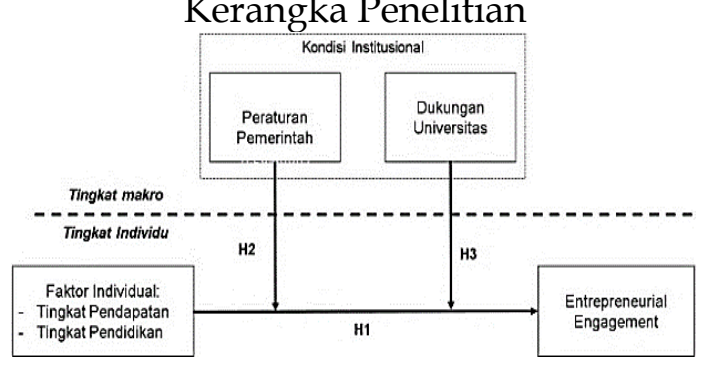

Terdapat faktor-faktor status sosial ekonomi keluarga yang turut ikut membangun rasa ingin berwirausaha antara lain: 1) tingkat pendidikan, 2) tingkat pendapatan, dan 3) tingkat pekerjaan (Abdulsyani, 2012). Penelitian yang dilakukan oleh (Shelton, 2010) menunjukkan bahwa orang dengan pendapatan rendah atau pendidikan terbatas cenderung menghadapi hambatan signifikan untuk mengidentifikasi dan merebut peluang wirausaha. 


\section{Hipotesis 1}

Faktor individual:

(a) Tingkat pendapatan

(b) Tingkat pendidikan

berpengaruh terhadap entrepreneurial engagement.

\section{Hipotesis 2}

Kondisi institusional yaitu kebijakan pemerintah berpengaruh terhadap hubungan antara faktor individual

a. Tingkat pendapatan

b. Tingkat pendidikan

Dengan entrepreneurial engagement.

\section{Hipotesis 3}

Kondisi institusional yaitu dukungan universitas berpengaruh terhadap hubungan antara faktor individual

a. Tingkat pendapatan

b. Tingkat pendidikan

Dengan entrepreneurial engagement.

\section{METODE PENELITIAN Jenis Penelitian}

Metode penelitian yang dipergunakan adalah metode penelitian deskriptif dan penelitian kausal. Metode deskriptif dirancang untuk mengumpulkan informasi tentang keadaan yang nyata saat penelitian ini dilakukan. Tujuannya adalah untuk mendapatkan gambaran umum tentang karakteristik populasi.

\section{Sampel Penelitian}

Penelitian ini dilakukan di Jakarta, ibukota Indonesia, dari Januari sampai Maret 2017. Populasi penelitian adalah anggota Kadin di DKI Jakarta dengan pertimbangan bahwa Kadin merupakan organisasi pengusaha, tempat coaching, komunikasi, informasi, representatif, konsultasi, advokasi wirausaha Indonesia dalam memperkuat kewirausahaan Indonesia yang berdaya saing.
Peneliti menggunakan sampel acak untuk memilih sampel dari populasi yang bertujuan untuk merepresentasikan populasi dan mengurangi peluang bias dari proses pemilihan.

Dalam penelitian ini, peneliti menghitung ukuran sampel menggunakan rumus sebagai berikut

$$
\begin{gathered}
s s=\frac{Z^{2} \times(p) \times(1-p)}{c^{2}} . \\
n e w s s=\frac{s s}{1+\frac{s s-1}{\text { population }}}
\end{gathered}
$$

Berdasarkan hasil perhitungan, ukuran sampel dalam penelitian sebanyak 345 sampel.

\section{Desain Penelitian}

Penelitian ini menggunakan dua variabel independen yaitu tingkat pendapatan dan tingkat pendidikan dan satu variabel dependen yaitu entrepreneurial engagement.

Variabel moderasi dalam hal ini dalah kebijakan pemerintah (Dimensi institusional) dan dukungan universitas (dimensi kognitif). Penggunaan variabel moderasi ini untuk mengeksplorasi apakah kebijakan pemerintah dan dukungan universitas berpengaruh terhadap hubungan antara faktor individual yaitu tingkat pendapatan dan tingkat pendidikan terhadap entrepreneurial engagement.

\section{Operasionalisasi Variabel}

Operasionalisasi variabel penelitian dapat dikemukakan sebagai berikut:

1. Variabel tingkat pendapatan adalah banyaknya penerimaan yang dinilai dengan satuan uang yang dapat dihasilkan seseorang dalam periode tertentu.

2. Variabel tingkat pendidikan. Tingkat pendidikan adalah suatu proses jangka panjang yang menggunakan prosedur sistematis dan terorganisir, 
yang mana tenaga kerja manajerial mempelajari pengetahuan konseptual dan teoritis untuk tujuan-tujuan umum (Andrew E. Sikula dalam Mangkunegara (2003).

3. Variabel dukungan pemerintah. Kebijakan pemerintah adalah seperangkat keputusan yang saling berhubungan, diambil oleh seorang atau sekelompok aktor politik berkenaan dengan pemilihan tujuan dan sarana pencapaiannya dalam suatu situasi khusus dimana keputusan-keputusan itu seharusnya, secara prinsip, berada dalam kekuasaan para aktor politik tersebut. Sedangkan kebijakan pemerintah mempunyai pengertian baku yaitu suatu keputusan yang dibuat secara sistematik oleh pemerintah dengan maksud dan tujuan tertentu yang menyangkut kepentingan umum

4. Variabel dukungan universitas. Universitas tidak hanya menghasilkan sumber daya manusia tetapi juga berfungsi sebagai tempat di mana para peneliti dan profesor dapat mengajar dan melakukan penelitian. Universitas dapat berkontribusi pada inovasi dan kewirausahaan lokal dengan menyediakan sumber daya manusia, menghasilkan pengetahuan baru yang mungkin mengandung peluang wirausaha, dan terlibat dalam layanan masyarakat terutama dalam pelatihan pengetahuan bisnis (Qian, Acs, \& Stough, 2013).

5. Variabel entrepreneurial engagement diukur sebagai variabel komposit multidimensi, yang terdiri dari tiga indikator formatif berdasarkan kriteria dalam Jarvis, et. al. (2003). Tiga indikator formatif, yang berasal dari GEM (Global Entrepreneurship Monitor) APS, mewakili keterlibatan individu dalam salah satu dari tiga kegiatan yang mencakup penciptaan bisnis baru: menemukan, mengevaluasi, dan mengeksploitasi peluang wirausaha.

Kekuatan dari penelitian terletak pada instrument yang digunakan dalam mengumpulkan data. Kuesioner dapat disusun dengan berbagai cara.

Penelitian ini mengadopsi instrument penelitian dari kuesioner yang telah ada dan digunakan pada penelitian sebelumnya sehingga telah melalui proses piloting.

Bagian pertama dari kuisioner bertujuan untuk menjabarkan profil demografi sampel, mencakup nama, jenis kelamin, usia, dan status pekerjaan. Pertanyaan-pertanyaan terkait profil demografi diajukan untuk mendapatkan gambaran karakteristik demografi sampel (Kyndt \& Baert, 2015).

Bagian kedua dari kuisioner berhubungan dengan bagaimana faktor individual, mencakup tingkat pendapatan dan pendidikan, berpengaruh terhadap entrepreneurial engagement (Lim, Oh, \& Clercq, 2016) di Indonesia.

Bagian ketiga dari kuesioner berhubungan dengan bagaimana kondisi institusional, mencakup kebijakan pemerintah dan dukungan universitas, dalam mempengaruhi entrepreneurial engagement (Lim, Oh, \& Clercq, 2016) di Indonesia. Responden diminta untuk mengisi bagian ketiga dari kuesioner berdasarkan pada Skala Likert terdiri atas pernyataan yang disertai dengan lima pilihan jawaban yaitu "sangat tidak setuju" $=1$, "tidak setuju" = 2, "netral" = 3, "setuju" $=4$, atau "sangat setuju" = 5 .

Bagian keempat dari kuisioner berhubungan dengan entrepreneurial engagement di Indonesia. Untuk mengukurnya, peneliti menggunakan indikator kewirausahaan terdiri atas 
penemuan, evaluasi, dan eksploitasi. Responden diminta untuk mengisi bagian keempat dari kuisioner berdasarkan pada Skala Likert yaitu "sangat tidak setuju" $=1$, "tidak setuju" = 2, "netral" = 3, "setuju" = 4 , atau "sangat setuju" $=5$.

\section{Metode Analisis}

Metode analisis yang dipergunakan dalam penelitian ini adalah analisis deskriptif dan regresi. Penelitian ini mengadopsi pertanyaan berdasarkan literatur sebelumnya. Oleh karena itu, kuesioner yang digunakan untuk mengukur data menghasilkan data yang valid.

Uji reliabilitas adalah untuk melihat apakah rangkaian kuesioner yang dipergunakan untuk mengukur suatu konstruk tidak mempunyai kecenderungan tertentu. Suatu kuesioner dikatakan reliable atau handal jika jawaban seseorang terhadap pernyataan adalah konsisten dan stabil dari waktu ke waktu (Ghozali, 2009). Uji Reliabilitas menggunakan metode Alpha Cronbach. Dengan degree of freedom $(\mathrm{df})=(\mathrm{n}-2)$ dan $\mathrm{a}$ $=0,05$ maka jika $r_{\text {alpha }}$ positif dan $r_{a l p h a}>r_{\text {tabel, }}$ pertanyaan dinyatakan reliabel atau jika $r_{\text {alpha }}$ positif dan $r_{a l p h a} \leq r_{\text {tabel }}$, pertanyaan dinyatakan tidak reliabel.

Metode analisis deskriptif adalah suatu metode yang berfungsi untuk mendeskripsikan atau memberi gambaran terhadap objek yang diteliti melalui data atau sampel yang telah terkumpul sebagaimana adanya tanpa melakukan analisis dan membuat kesimpulan yang berlaku untuk umum (Sugiyono, 2009).

Untuk menguji hipotesis 1, Faktor individual meliputi tingkat pendapatan dan tingkat pendidikan berpengaruh terhadap entrepreneurial engagement, peneliti melakukan uji regresi sederhana.

Alat analisis yang digunakan peneliti untuk pengujian hipotesis 2 dan 3 , yaitu
Regresi Linier Berganda (Multiple Regression), dengan variable moderasi. Variabel moderasi atau moderating variable adalah variabel independen yang akan memperkuat atau memperlemah hubungan antara variabel independen lainnya terhadap variabel dependen.

Pengujian ini untuk mengetahui apakah kebijakan pemerintah berpengaruh terhadap hubungan antara faktor individual dengan entrepreneurial engagement. Demikian halnya dengan kondisi institusional yaitu dukungan universitas apakah berpengaruh terhadap hubungan antara faktor individual dengan entrepreneurial engagement.

Sebelum pengujian tersebut dilakukan uji asumsi klasik sebagai persyaratan statistik yang harus dipenuhi pada analisis regresi linear berganda yang berbasis ordinary least square (OLS). Tujuannya adalah agar tidak ada pelanggaran terhadap asumsi-asumsi klasik antara lain normalitas, multikolinieritas, heterokedastisitas (Gujarati, 1992) agar model penelitian memberikan hasil estimasi yang terbaik atau BLUE (Best Linier Unbiased Estimator).

Peneliti menggunakan bantuan software SPSS (Statistical Package for Social Sciences) untuk menjalankan analisis tersebut di atas.

\section{HASIL PENELITIAN DAN \\ PEMBAHASAN}

Hasil Penelitian

Pengujian Hipotesis 1(a)

Hasil pengujian menunjukkan bahwa faktor individual tingkat pendapatan berpengaruh terhadap entrepreneurial engagement. Dari jumlah responden 315 tanpa nilai yang hilang, koefisien korelasinya adalah 0,751. Signifikansi korelasi adalah $<0,05$. Itu berarti bahwa ada korelasi yang signifikan antara tingkat 
pendapatan dengan entrepreneurial engagement

Modal keuangan sebagai variabel independen memberikan kontribusi 56,5\% untuk entrepreneurial engagement ( $R$ Square $=0,565)$. Dengan nilai signifikansi $<0,05$, berarti ada hubungan yang positif signifikan antara modal finansial dan entrepreneurial engagement ( $\beta$ adalah 0,371 )

Tabel 1.

Regresi Tingkat Pendapatan

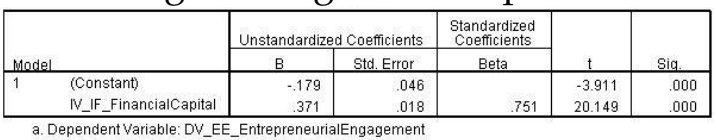

Pengujian Hipotesis 1 (b)

Faktor individual tingkat pendidikan berpengaruh terhadap entrepreneurial engagement. Dengan jumlah responden 315 tanpa nilai yang hilang, koefisien korelasinya adalah 0,530. Signifikansi korelasi adalah $<0,05$. Itu berarti bahwa ada korelasi yang signifikan antara modal intelektual dan entrepreneurial engagement.

Selain itu, sebagian besar responden yang bersedia memenuhi aspirasi wirausaha mereka terkait dengan pemegang gelar sarjana strata 2 . Berdasarkan skala 1 - 4, hasilnya menunjukkan rata-rata 2,7397.

Modal intelektual sebagai variabel independen memberikan kontribusi $28,1 \%$ terhadap entrepreneurial engagement ( $\mathrm{R}$ Square $=0,281$ ).

Hasil analisis regresi antara modal intelektual (tingkat pendidikan) dan entrepreneurial engagement menunjukkan bahwa terdapat pengaruh positif signifikan antara modal intelektual dan entrepreneurial engagement ( $\beta$ adalah 0,223 ). Tabel 2.

Regresi Tingkat Pendidikan

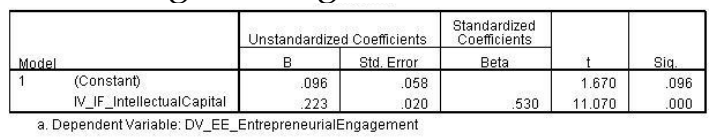

Pengujian Hipotesis 2 (a)

Penghitungan statistic menunjukkan bahwa kebanyakan responden bersedia memenuhi aspirasi wirausaha mereka. Berdasarkan skala 0 - 1, hasilnya menunjukkan rata-rata 0,7058. Variabel moderasi dihitung dengan perkalian antara dimensi regulasi dan modal finansial.

Kondisi institusional yaitu kebijakan pemerintah berpengaruh terhadap hubungan antara faktor individual tingkat pendapatan dengan entrepreneurial engagement. Ditunjukkan dengan koefisien korelasi sebesar 0,545.

Dimensi regulasi sebagai variabel moderasi dari tingkat pendidikan dan entrepreneurial engagement memberikan kontribusi $29,7 \%$.

Terdapat hubungan positif antara dimensi regulasi sebagai variabel moderasi modal keuangan dan entrepreneurial engagement dengan $\beta$ 0,111.

Tabel 3.

Regresi Hipotesis 2 (a)

Coefficients $^{\mathrm{s}}$

\begin{tabular}{|c|c|c|c|c|c|c|}
\hline \multirow[b]{2}{*}{ Model } & & \multicolumn{2}{|c|}{ Unstandardized Coefficients } & \multirow{2}{*}{$\begin{array}{c}\begin{array}{c}\text { Standardized } \\
\text { Coefficients }\end{array} \\
\text { Beta } \\
\end{array}$} & \multirow[b]{2}{*}{ \pm} & \multirow[b]{2}{*}{ Sig. } \\
\hline & & B & Std. Error & & & \\
\hline 1 & (Constant) & -.175 & .043 & & -4.033 & .000 \\
\hline & FC_RD & .111 & .005 & .768 & 21.200 & .000 \\
\hline
\end{tabular}

\section{Pengujian Hipotesis 2 (b)}

Kondisi institusional yaitu kebijakan pemerintah berpengaruh terhadap hubungan antara faktor individual tingkat pendidikan dengan entrepreneurial engagement. Ditunjukkan dengan koefisien korelasi sebesar 0,545, dengan tingkat signifikansi $<0,05$. Artinya terdapat korelasi yang signifikan antara dimensi peraturan sebagai variabel moderasi dari variabel modal intelektual dan entrepreneurial engagement.

Dimensi regulasi sebagai variabel moderasi modal intelektual dan entrepreneurial engagement memberikan kontribusi $29,7 \%$. 
Tabel 4.

Regresi Hipotesis 2 (b)

coefficients $^{*}$

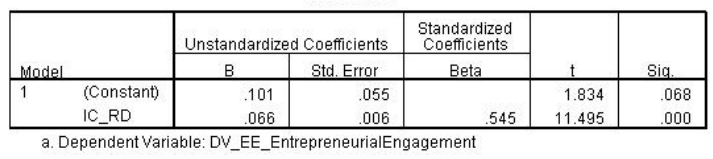

Hubungan antara dimensi regulasi sebagai variabel moderasi terhadap hubungan antara modal intelektual (tingkat pendidikan) dan entrepreneurial engagement adalah positif degan koefisien $\beta$ sebesar 0.066 .

\section{Pengujian Hipotesis 3 (a)}

Kondisi institusional yaitu dukungan universitas berpengaruh terhadap hubungan antara faktor individual tingkat pendapatan dengan entrepreneurial engagement.

Dimensi kognitif sebagai variabel moderasi modal keuangan dan entrepreneurial engagement memberikan kontribusi 43,1\%. Terdapat hubungan yang signifikan dan positif antara dimensi kognitif sebagai variabel moderasi modal keuangan dan entrepreneurial engagement.

Tabel 5.

Koefisien Hipotesis 3 (a)

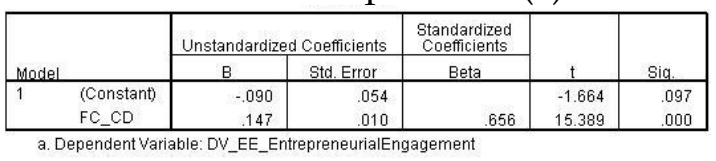

$\beta$ adalah 0,147, yang berarti ada hubungan positif antara dimensi kognitif sebagai variabel pemoderasi modal keuangan dan entrepreneurial engagement.

\section{Pengujian Hipotesis 3 (b)}

Variabel moderasi dihitung dengan perkalian antara dimensi kognitif dan modal intelektual. Kondisi institusional yaitu dukungan universitas berpengaruh terhadap hubungan antara faktor individual tingkat pendidikan dengan entrepreneurial engagement.

Dimensi kognitif sebagai variabel moderasi modal intelektual dan entrepreneurial engagement memberikan kontribusi hanya $16,8 \%$.

Table 6.

Koefisien Hipotesis 3 (b)

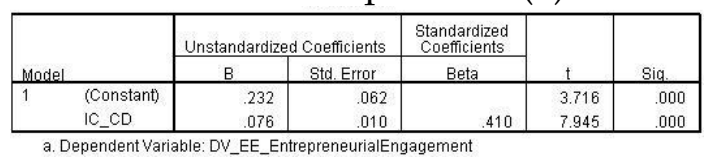

Nilai $\beta$ 0,076, yang berarti ada hubungan positif antara dimensi kognitif sebagai variabel pemoderasi modal intelektual dan entrepreneurial engagement.

\section{Pembahasan}

Penelitian ini memberikan pemahaman yang lebih lengkap tentang bagaimana modal keuangan dan sumber daya manusia yang dimiliki oleh individu mempengaruhi keterlibatan mereka dalam kewirausahaan, terutama dalam hal bagaimana pengaruh ini tergantung pada konteks kelembagaan yang lebih luas. Seperti yang diharapkan, peneliti menemukan efek positif langsung dari modal keuangan individu (pendapatan rumah tangga) dan modal manusia (tingkat pendidikan) pada keterlibatan individu dalam kewirausahaan (entrepreneurial engagement).

Dari hasil pengujian, tingkat pendapatan berefek positif langsung terhadap entrepreneurial engagement. Serupa dengan penelitian (Clercq, Lim, \& Oh, 2013) yang menunjukkan efek positif yang kuat dari kekayaan individu pada kewirausahaan. Meski beberapa penelitian tidak menemukan hubungan yang signifikan antara pendapatan rumah tangga atau kekayaan dan kemungkinan menjadi pengusaha (Hurst \& Lusardi, 2004) (Kim, Aldrich, \& Keister, 2006).

Pendapatan rumah tangga berkaitan dengan modal finansial yang menjadi salah satu pertimbangan individu dalam kewirausahaan. Level finansial bisa menjadi penghalang individu dalam proses kewirausaaan. Kelompok dengan 
penghasilan tinggi biasanya memiliki akses lebih berkualitas sehingga dapat meningkatkan peluang wirausaha.

Di sisi lain tingkat pendidikan memegang peranan penting terhadap entrepreneurial engagement. Meski hasil penelitian yang berbeda menunjukkan bahwa pendidikan formal individu mungkin tidak selalu memprediksi keberhasilan dalam kegiatan kewirausahaan (Manev, Gyoshev, \& Manolova, 2005)

Individu yang berpendidikan lebih baik cenderung mendapatkan akses pendidikan kewirausahaan melalui lembaga pendidikan tinggi (universitas), yang mana akan berdampak lebih memperhatikan pada penciptaan, pertumbuhan, dan manajemen bisnis baru.

Pada konteks kelembagaan atau level makro, faktor institusional dalam bentuk kebijakan pemerintah maupun dukungan universitas, memperkuat hubungan antara faktor individu dan entrepreneurial engagement. Hasil ini berbeda dengan penelitian Lim, Oh, \& Clercq (2016) yang menggunakan sampel dari 22 emerging countries, di mana peran pendidikan tinggi pada entrepreneurial engagement hasil pengujiannya bervariasi bergantung pada kondisi kelembagaan peraturan, kognitif, dan normatif negara.

Kewirausahaan di negara-negara berkembang sering terhambat oleh birokrasi yang berlebihan, beban pajak yang tinggi, sistem pengumpulan pajak yang tidak efisien, peraturan perundangundangan yang tidak menentu, dan kegagalan untuk memenuhi komitmen hukum yang ada. Hambatan pengaturan seperti itu kemungkinan membuat lebih sulit bagi individu untuk memanfaatkan sumber daya pribadi mereka menuju kewirausahaan.

Bahwa dalam negara dengan lingkungan regulasi yang menguntungkan, sumber daya individu dapat diterapkan secara lebih efektif untuk mengenali, mengevaluasi, dan mengeksploitasi peluang wirausaha.

\section{KESIMPULAN}

Dari hasil analisis dan pembahasan yang telah diuraikan, maka dapat ditarik kesimpulan sebagai berikut:

1. Faktor individu, tingkat pendapatan berpengaruh secara signifikan dan positif terhadap entrepreneurial engangement.

2. Faktor individu tingkat pendidikan, berpengaruh secara signifikan dan positif terhadap entrepreneurial engangement.

3. Kondisi insitusional yaitu kebijakan pemerintah secara signifikan berpengaruhi positif atau memperkuat hubungan antara faktor individu dan entrepreneurial engangement.

4. Kondisi insitusional yaitu dukungan universitas, secara signifikan berpengaruhi positif atau memperkuat hubungan antara faktor individu dan entrepreneurial engangement.

\section{SARAN}

Penelitian ini dilakukan terbatas di Jakarta, ibukota Indonesia. Sehingga tidak dapat merepresentasikan seluruh wilayah di Indonesia. Terdapat perbedaan kebijakan dan peraturan antara Jakarta dan wilayah lainnya. Meski demikian, penelitian ini dapat dijadikan platform penelitian selanjutnya untuk menyelidiki lebih lanjut kondisi insitusional akan memiliki pengaruh terhadap entrepreneurial engangement di wilayah lainnya selain Jakarta.

Selain itu, terdapat banyak faktor individual terlepas dari tingkat pendapatan dan pendidikan terhadap 
entrepreneurial engangement, begitu juga dengan variabel pada tingkat makro, seperti asumsi sosial pada suatu wilayah, dapat dijadikan pengembangan untuk penelitian selanjutnya.

\section{DAFTAR PUSTAKA}

Abdulsyani. (2012). Sosiologi Skematik, Teori dan Terapan. Jakarta: Bumi Aksara.

Autio, E., \& Acs, Z. (2010). Institutional influences on strategic entrepreneurial behavior. Strategic Entrepreneurship Journal, 4, 234-251.

Baumol, W., Litan, R., \& Schramm, C. (2009). Good capitalism, bad capitalism and the economics of growth and prosperity. New Haven, CT: Yale University Press. doi:10.5840/beq200818219

Bruton, G., Ahlstrom, D., \& Li, H. (2010). Institutional theory and entrepreneurship: Where are we now and where do we need to move in the future? Entrepreneurship Theory and Practice, 34, 421-440. doi:10.1111/j.1540-6520.2010.00390.x

Busenitz, L., Gomez, C., \& Spencer, J. (2000). Country institutional profiles: Unlocking entrepreneurial phenomena. Academy of Management Journal, 43, 994-1003. doi:10.2307/1556423

Clercq, D. D., Lim, D. S., \& Oh, C. H. (2013). Individual-Level Resources and New Business Activity: The Contingent Role of Institutional Context. Entrepreneurship Theory \& Practice, $37(2)$, 303-330. doi:10.1111/j.1540$6520.2011 .00470 . x$

Economics, T. (2016). Trading Economics. Retrieved from https://tradingeconomics.com

Furinto, A. (2015, May 26). On making our entrepreneurs less entrepreneurial. Retrieved from The Jakarta Post: https://www.thejakartapost.com/ne ws/2015/05/26/on-making-ourentrepreneurs-lessentrepreneurial.html
Ghozali, I. (2009). Aplikasi Analisis Multivariate dengan Program SPSS. Semarang: Badan Penerbit UNDIP.

Gujarati, D. (1992). Econometric Basic. Singapura: Mc Graw-Hill.

Haynie, J., Shepherd, D., \& McMullen, J. (2009). An opportunity for me? The role of resources in opportunity evaluation decisions. Journal of Management Studies, 46(3), 337-361. doi:10.1111/j.1467-6486.2009.00824.x

Hurst, E., \& Lusardi, A. (2004). Liquidity constraints, household wealth, and entrepreneurship. Journal of Political Economy, 112(2), 319-347. doi:10.2139/ssrn.414780

lyigun, M., \& Owen, A. (1998). Risk, entrepreneurship and human-capital accumulation. American Economic Review, 88(2), 454-457. Retrieved January 7, 2017, from https://www.researchgate.net/publi cation/4980808_Risk_Entrepreneurshi P_and_Human_Capital_Accumulati on

Jansen, S., Zande, T., Brinkkemper, S., \& Varma, V. (2015). How education, stimulation, and incubation encourage student entrepreneurship: Observations from MIT, IIIT, and Utrecht University. The International Journal of Management Education, 13 , 170-181. doi:10.1016/j.jime.2015.03.001

Jarvis, C., MacKenzie, S., \& Podsakoff, P. (2003). A critical review of construct indicators and measurement model misspecification in marketing and consumer research. Journal of Consumer Research, 30(2), 199-218. doi:10.1086/376806

Kim, P. H., Aldrich, H. E., \& Keister, L. A. (2006). Access (not) denied: The impact of financial, human, and cultural capital on entrepreneurial entry in the United States. Small Business Economics, 27(1), 5-22. doi:10.1007/s1 $1187-006-0007-x$

Kostova, T., \& Roth, K. (2002). Adoption of an organizational practice by subsidiaries of multinational corporations: Institutional and 
relational effects. Academy of Management Journal, 45(1), 215-233. doi:10.5465/3069293

Kyndt, E., \& Baert, H. (2015). Entrepreneurial competencies: Assessment and predictive value for entrepreneurship. Journal of Vocational Behavior, 90, 13-25. doi:0.1016/j.jvb.2015.07.002

Lau, C., \& Busenitz, L. (2001). Growth intentions of entrepreneurs in a transitional economy: The People's Republic of China. Entrepreneurship Theory and Practice, 26, 5-20. doi:10.1177/104225870102600101

Levie, J., \& Autio, E. (2008). A theoretical grounding and test of the GEM model. Small Business Economics, $31(3), \quad 235-263$. doi:10.1007/s11187008-9136-8

Lim, D., Oh, C., \& Clercq, D. (2016). Engagement in entrepreneurship in emerging economies: Interactive effects of individual-level factors and institutional conditions. International Business Review, 25, 933-945. doi:10.1016/j.ibusrev.2015.12.001

Lim, D., Oh, C., \& Clercq, D. (2016). Engagement in entrepreneurship in emerging economies: Interactive effects of individual-level factors and institutional conditions. International Business Review, 25, 933-945. doi:10.1016/j.ibusrev.2015.12.001

Manev, I. M., Gyoshev, B. S., \& Manolova, T. S. (2005). The role of human and social capital and entrepreneurial orientation for small business performance in a transitional economy. International Journal of Entrepreneurship and Innovation Management, 5(3), 298-318. doi:10.1504/IJEIM.2005.006531

Mangkunegara, A. P. (2003). Perencanaan dan Pengembangan Sumber Daya Manusia. Bandung: Refika Aditama.
Praditya, I. I. (2016, October 26). Kemudahan Berbisnis Indonesia Naik ke Peringkat 91. Retrieved from /www.liputan6.com: https://www.liputan6.com/bisnis/rea d/2635673/kemudahan-berbisnisindonesia-naik-ke-peringkat-91

Qian, H., Acs, Z., \& Stough, R. (2013). Regional systems of entrepreneurship the nexus of human capital, knowledge, and new firm formation. Journal of Economic Geography, 13, 559-587. doi:10.1093/jeg/lbs009

Shelton, L. (2010). Fighting an uphill battle: Expansion barriers, intra-industry social stratification, and minority firm growth. Entrepreneurship, Theory and Practice, 34, 379-398. doi:10.1111/j.1540-6520.2010.00379.x

Shepherd, D. A. (2010). Multilevel entrepreneurship research: Opportunities for studying entrepreneurial decision making. Journal of Management, 37,, 37, 412420. doi:10.1177/0149206310369940

Souitaris, V., Zerbinati, S., \& Al-Laham, A. (2007). Do entrepreneurship programmes raise entrepreneurial intentions of science and engineering students? The effects of learning, inspiration and resources. Journal of Business Venturing, 22, 566-591. doi:10.1016/j.jbusvent.2006.05.002

Sugiyono. (2009). Metode Penelitian Kuantitatif, Kualitatif dan R\&D. Bandung: Alfabeta.

Syaifuddin, D. T. (2016). Kewirausahaan. Yogyakarta: Wijaya Mahadi Karya.

Ucbasaran, D., Westhead, P., \& Wright, M. (2008). Opportunity identification and pursuit: Does an entrepreneur's human capital matter? Small Business Economics, Springer, 30(2), 153-173. doi:10.1007/s $11187-006-9020-3$ 